\title{
Evolution of stress hormones and proteins in relation to developmental origins of health and disease
}

\author{
Viktor I Goudochnikov* \\ Council of International Society for DOHaD, Santa Maria-RS, Brazil
}

\begin{abstract}
The mini-review is presented about the evolution of stress hormones (the components of hypothalamo-pituitary-adrenal axis) and stress proteins (heat shock proteins and others), as related to the concept of developmental origins of health and disease. The data on somatic growth retardation by glucocorticoids as mediators and targets of programming / imprinting phenomena are discussed in evolutionary aspect. Finally, two theoretical constructs are briefly introduced, the onto- and phylopatogenic model, with the last one having some perspectives of elaboration, as referred to biological evolution.
\end{abstract}

\section{Introduction}

At present two different types of stress are discussed: physiologic and cellular one [1]. Physiologic stress is known to occur on the level of the whole organism of animals and humans, and its mechanisms involve the following hormones: corticoliberin (corticotropin-releasing factor, CRF) and arginine-vasopressin from the hypothalamus, adrenocorticotropic hormone (ACTH) from hypophysis and glucocorticoids (GC: cortisol, corticosterone) from adrenal cortex, composing the so called hypothalamo-pituitary-adrenal (HPA) axis. In addition, mechanisms of physiologic stress involve also catecholamines (adrenaline, noradrenaline), as well as oxytocin and many other bioregulators, but nevertheless, the fundamental role is attributed to HPA hormones [1,2].

On the other hand, cell reactions to stress are realized by means of so-called stress proteins, mainly by heat shock proteins (HSP), as well as metallothioneins (MT), annexins and some others. Today the interactions between stress hormones and proteins continue to be poorly understood $[1,2]$.

Beginning from the end of eighties of the last century, the concept emerged on developmental origins of health and disease (DOHaD), in which the central position is occupied by programming / imprinting phenomena. These phenomena take place in those situations when the action of certain factors including stress, in perinatal and some other periods of development provokes long-term consequences expressed partially in higher predisposition to a number of disorders already in adult state and in senescence. There exist important data showing principal role of GC in programming / imprinting phenomena [3,4].

However, quite reasonable question can emerge: when these phenomena appeared in the evolution? Obviously, this question is related to evaluation of the phylogeny of GC and other HPA hormones and perhaps, of stress proteins also. Therefore, in the present work we aimed at description of the evolution of stress hormones and proteins, focusing the main attention on the role of GC and other hormones in programming / imprinting phenomena in the light of $\mathrm{DOHaD}$ concept.

\section{Evolution of hypothalamo-pituitary-adrenal axis hormones}

During the last decades significant progress occurred in our understanding of the phylogeny of stress hormones. This progress was related principally to determination of primary structures of hormonal polypeptides in various species of animals and to sequencing of DNA in these species, as well as to using special computer softwares for comparisons of the sequences of aminoacid residues in polypeptides and of nucleotides in DNA, in order to reveal the degree of their similarity. Although GC are steroid hormones and therefore, such methods are not applicable to them, nevertheless, protein receptors of GC and their genes can be compared by these technologies.

And here quite interesting surprise is waiting for us: receptors of GC and enzymes for their biosynthesis were not found in the invertebrates [5], hence these hormones are unlikely to participate in programming / imprinting phenomena, even if such phenomena really exist in these species. Moreover, possible participation of GC in mechanisms of aging [6] also becomes doubtful for such species.

What for another stress hormones? Phylogeny of corticoliberin (CRF) and related peptides: urocortin / urotensin I and urocortins type 2 and 3, as well as of their receptors CRF1 and CRF2 may be associated with two genome duplications during appearance of vertebrates in evolution [7,8]. Phylogeny of ACTH precursor proopiomelanocortin (POMC) is also associated with two genome duplications and emergence of related polypeptides: proenkephalin, prodynorphin and proorphanin [9], whereas the phylogeny of POMC is related probably to so called tandem duplication of a gene, in this case of melanocytestimulating hormone-MSH [10].

*Correspondence to: Viktor I Goudochnikov, Rua Matoso Camara 73, CEP 97050-500, Santa Maria-RS, Brazil, E-mail: victorig40@hotmail.com

Key words: glucocorticoids, heat shock proteins, growth, stress, ontogeny, programming / imprinting

Received: March 01, 2019; Accepted: March 19, 2019; Published: March 25 2019 
The evolution of 4 out of 5 types of melanocortin receptors (MC1R, MC2R, MC3R, MC4R) also appears to involve two genome duplications, whereas the emergence of MC5R involves, perhaps, tandem duplication of a gene. It should be noted, nevertheless, that only the type MC2R participates in binding and signaling of ACTH, whereas other types are receptors of various MSH forms. For such aim a special factor, melanocortin receptor-associated protein (MRAP) type 1 is employed, in order to enhance the affinity of MC2R to ACTH. Probably, coevolution of POMC and related protein precursors may occur, in parallel with melanocortin receptors [10].

What for receptors of GC and other steroid hormones, in this case, at the very beginning nuclear receptors emerge for binding lipophilic compounds with low affinity [5], thereafter receptors for estrogens and progestins appear first, being followed by receptors for androgens and corticoids [11], and corticoid receptors are involved at first in mineralocorticoid regulation and only later on separate receptors for mineralocorticoids and glucocorticoids emerge. The appearance in evolution of specialized mineralocorticoid hormone - aldosterone is rather late evolutionary event, and for blocking the action of GC on mineralocorticoid receptors a special mechanism is used on the basis of enzymatic inactivation of GC by means of 11beta-hydroxysteroid dehydrogenase on pre-receptor stage.

Let's discuss briefly now the evolution of principal stress proteins.

\section{Phylogeny of heat shock proteins, metallothioneins and annexins}

In contrast to hormones of physiologic stress, many proteins of cell stress are found in the most primitive early life forms on the planet Earth. In fact, HSP were identified practically in all species studied, from bacteria to higher metazoans [12]. Probably, this situation is related to extremely important their functions in proteostasis, i.e. providing stability and renaturation of various proteins, as well as in proteolysis with ubiquitin participation in those cases when renaturation cannot be performed. Therefore it is not surprising that the degree of similarity of HSP70 and HSP90 in E.coli and vertebrates is close to 50\%, whereas yeast cells already possess practically all necessary HSP [13].

In addition, MT are also quite ancient proteins, although the authors that analyzed their phylogeny, admit the complexity of such task, because of heterogeneity of MT, expressed in different affinity to $\mathrm{Zn}^{2+}$ and $\mathrm{Cu}^{+}$ions [14]. Nevertheless, the emergence of 4 types of MT in higher vertebrates appears to involve also two genome duplications. However, as in all other variants of such explanation, the next question would be: how did the most ancient, early precursor of MT emerge?

To this aim, an attempt was made for analysis of life evolution on the planet Earth, beginning from the very onset of its emergence [14] and separating the whole time scale to three epochs, really giant in their extension:

- with high Fe content and low concentrations of $\mathrm{Zn}$ and $\mathrm{Cu}$ in water, when bacteria species with anaerobic metabolism dominated, due to atmosphere without oxygen (from 4 to 2,4 billion years ago);

- with increasing $\mathrm{Zn}$ and $\mathrm{Cu}$ concentration and decreasing $\mathrm{Fe}$ content in separate aqueous compartments with more oxygenated atmosphere, when aerobic bacteria and unicellular eukaryotes emerged (from 2,4 to 0,5 billion years ago);

- with low $\mathrm{Fe}$ content and rather high $\mathrm{Zn}$ and $\mathrm{Cu}$ concentrations in water, when metazoans emerged in fully oxygenated atmosphere (from 0,5 billion years ago to the moment close to present).
Therefore, the emergence and phylogeny of MT may be related to transition from the first out of these 3 epochs to the second one and partially, from the second to third one, in order to providing the transport of $\mathrm{Zn}$ and $\mathrm{Cu}$, in association with the necessity of regulation by their ions of gene expression and various enzymatic activities.

What for annexins / lipocortins, they appear to exist only in metazoans, and their phylogeny involved probably tandem duplication of a gene [15].

Let's discuss now, how the phylogeny of stress hormones and proteins may be related to programming / imprinting phenomena, as well as to aging and strategies of life history.

\section{DOHaD concept, aging and the evolution of stress hormones and proteins}

If GC are involved in programming / imprinting phenomena as principal factors, then it becomes clear that such phenomena are possible only in vertebrates. As a matter of fact, one of main details of such GC involvement is growth inhibition in organs and whole body, with concomitant induction of mature, more differentiated tissue phenotype.

It is interesting that one of the authors who demonstrated growthinhibitory GC action was a pharmacologist from St. Petersburg, M.V. Nezhentsev, using hydrocortisone administered to rats [16]. We were able to evaluate growth-inhibitory action of more active GC dexamethasone in rats only in the nineties of the last century and at the beginning of the current one $[17,18]$.

However, in two small studies we could show also growth-inhibitory influence of dexamethasone in chicken [19] and canine pups [20], and in the first case we observed short-term growth retardation by means of miniknemometry, whereas in the second case the disruption of growth proportionality in the members was established under the influence of GC.

Moreover, we were able to collect together rather scarce literature data about growth-inhibitory GC action in various species [19]. All these data indicate the conservation in evolution of the mechanism of GC involvement in programming / imprinting phenomena on the basis of growth retardation.

What for aging, the role of GC and stress in its occurrence is not totally clear even in higher mammals and humans [6]. However, the suggestion is possible that species with greater longevity possess finely regulated reactions to stress, without inducing the negative allostatic consequences in the long term. Nevertheless, significant efforts still should be made for revealing the role of stress and its hormonal and proteinaceous mediators in phylogenetic aspects of aging. This topic becomes even more important, if to take into account that in modern gerontology the data obtained on species with short lifespan, like nematodes and Drosophila are considered as significant for other species, in spite of the fact that these invertebrates have principal differences with vertebrates and humans in the mechanisms of stress, for example, because of the absence of GC in the former.

In addition, many invertebrates, as well as a number of vertebrates have principally different (as compared to humans and some other vertebrates) strategies of redistribution of energetic and material resources between the maintenance of the body, growth and reproduction (the so-called $\mathrm{r}$ - and $\mathrm{K}$-species) [21]. It is clear that not 
only the occurrence of aging is different in them, but the contribution of stress and its hormonal and proteinaceous mediators may be quite different also.

Finally, the strategies of life history may be quite different, what should be considered in the usage even of mammals like rats and mice as the models of hormonal regulation of ontogeny in humans. Indeed, taking into account that rats are born in less mature state, as compared to human, the administration of GC to neonatal rats, as a matter of fact, is modeling their use in the $3^{\text {rd }}$ trimester of gestation in humans or in premature newborns [22].

\section{Conclusion}

Therefore, even if the programming / imprinting phenomena are manifest by invertebrates, they should occur without participation of GC. What for vertebrates, the role of GC in such phenomena demonstrates evolutionary conservative mode, but it may represent some differences, as related to the strategies of life history.

Currently we are elaborating the ontopathogenic model in the framework of $\mathrm{DOHaD}$ concept. This model considers the pathogeny of various disorders during the whole ontogeny, with the possibility of programming / imprinting and embedding phenomena in critical periods of development, provoking the consequences till adult state and even senescence $[23,24]$. However, another theoretical model is possible, the phylopathogenic one [25], with multi- and intergenerational transfer of the risk of different pathologies. However, for its elaboration we should estimate at first the evolutionary aspects of various diseases.

\section{References}

1. Goudochnikov VI (2015) Role of stress proteins and hormones in bioregulation of ontogeny. Probl Endokrinol 61: 49-53.

2. Goudochnikov VI (2011) Hormonal mediators and proteins of stress: interrelations in ontogeny and phylogeny In: Congresso de Stress da ISMA-BR. Porto Alegre.

3. Goudochnikov VI (2012) Role of glucocorticoids in ontogeny: from developmental programming to aging. Rev Contexto Saude 12: 26-33.

4. Goudochnikov VI (2015) Role of hormones in perinatal and early postnatal development: Possible contribution to programming / imprinting phenomena. Russ $J$ Dev Biol 46: 237-245.

5. Markov GV, Laudet V (2011) Origin and evolution of the ligand-binding ability of nuclear receptors. Mol Cell Endocrinol 334: 21-30. [Crossref]

6. Goudochnikov VI (2011) The role of glucocorticoids in aging and age-related pharmacotherapy. Adv Gerontol 24: 48-53. [Crossref]

7. Chang CL, Hsu SYT (2004) Ancient evolution of stress-regulating peptides in vertebrates. Peptides 25: 1681-1688.
8. Lovejoy DA, de Lannoy L (2013) Evolution and phylogeny of the corticotropinreleasing factor (CRF) family of peptides: expansion and specialization in the vertebrates. J Chem Neuroanat 54: 50-56. [Crossref]

9. Navarro S, Soletto L, Puchol S, Rotllant J, Soengas JL, et al. (2016) 60 years of POMC: an evolutionary perspective. J Mol Endocrinol 56: T113-118. [Crossref]

10. Cortés R, Navarro S, Agulleiro MJ, Guillot R, García-Herranz V, et al. (2014) Evolution of the melanocortin system. Gen Comp Endocrinol 209: 3-10. [Crossref]

11. Thornton JW (2001) Evolution of vertebrate steroid receptors from an ancestral estrogen receptor by ligand exploitation and serial genome expansions. Proc Nat Acad Sci 98: 5671-5676.

12. Karlin S, Brocchieri L (1998) Heat shock protein 70 family: multiple sequence comparisons, function and evolution. J Mol Evol 47: 565-577.

13. Mager WH, Ferreira PM (1993) Stress response of yeast. Biochem J 290: 1-13. [Crossref]

14. Capdevila M, Atrian S (2011) Metallothionein protein evolution: a miniassay. J Biol Inorg Chem 16: 977-989. [Crossref]

15. Smith PD, Moss SE (1994) Structural evolution of the annexin supergene family. Trends Genet 10: 241-246. [Crossref]

16. Nezhentsev MV (1981) Effect of hydrocortisone on the growth of white rats at different age. Zh Evol Biokhim Fiziol 17: 154-158. [Crossref]

17. Goudochnikov VI (1997) Pathogeny of glucocorticoid-induced growth retardation evaluated in experimental studies using laboratory animals and cell cultures as models. NewsLab 22: 90-100.

18. Cassol V, Goudochnikov VI (2001) Growth retardation, without alteration of food consumption, in young rats treated with glucocorticoid in neonatal period. Rev Contexto Saude 1: 113-120.

19. Goudochnikov VI (2010) Growth regulation by corticoids in ontogeny and phylogeny In: 14. Simposio de Ensino Pesquisa e Extensao. Santa Maria: Unifra.

20. Baratto A, Miguel D, Muhlen EV, Bertolo E, Goudochnikov VI (2007) Acute effects of corticoid injected in neonatal period on growth proportionality in dogs: a case study In: 15. Seminario de Iniciacao Cientifica. Ijui: Unijui.

21. Denver RJ, Middlemis-Maher J (2010) Lessons from evolution: developmenta plasticity in vertebrates with complex life cycles. J Dev Orig Health Dis 1: 282-291.

22. Goudochnikov VI (2009) Glucocorticoid programming: prenatal or perinatal? J Dev Orig Health Dis 1: S182-S183.

23. Goudochnikov VI (2016) Role of thyroid hormones and iodine consumption in the ontopatogeny of various diseases: Focus on interactions with glucocorticoids and some endocrine disruptors. Clin Exp Thyroidol 2: 16-21.

24. Goudochnikov VI (2018) Emerging terms and concepts of pharmacotoxicologic programming / imprinting and embedding, as related to the ontopathogeny of respiratory and other disorders. EC Pulmonol Respir Med 7: 413-415.

25. Goudochnikov VI, Prokhorov LY (2016) Important contribution of perinatal nutrition and hormonal programming / imprinting to pathogenesis of age-related diseases. Probl Star Dolgolet 25: 50-58.

Copyright: (C)2019 Goudochnikov VI. This is an open-access article distributed under the terms of the Creative Commons Attribution License, which permits unrestricted use, distribution, and reproduction in any medium, provided the original author and source are credited. 